\title{
A Selection-route Model and Its Algorithm for Military Logistics Delivery in an Emergency
}

\author{
Wang guiqiang,Qi Jidong \\ Dept.of Handling Facilities \\ Military Transportation University \\ Tianjin, China ,300161
}

\author{
Zhang Yuyi, Li Jinhua, Yang Fuqian \\ Dept.of Handling Facilities \\ Military Transportation University \\ Tianjin, China ,300161
}

\begin{abstract}
A vehicle routing problem in a war is discussed, in which some routes may be destroyed uncertainly by competitor. A two-stage integer program model is constructed. The value of a route in a uncertain situation is analyzed. Find a method to simply the computation of the object value of the model. In the method, only the maximum value and the minimum value are countered into the object value. A two-stage taboo search algorithm is designed. In the end, an example is given.
\end{abstract}

Keywords- Emergency logistics, vehicle routing problem, uncertain decision, taboo search algorithm

\section{INTRODUCTION}

In the time of war, some bridges, tunnels and road hubs which play a key role in the traffic route might be sabotaged by the enemy at any time. The traffic time will be reduced by using these key bridges (tunnels)[1]. If these bridges were destroyed, the vehicles would have to take a roundabout way and even turn back. In such cases the traffic time would be increased. The same problem exists in the evacuation task in times of natural disaster. In the development of human history, the natural disasters such as earthquake, flood, typhoon and avalanche have led to the break-down of the traffic route. The 1995 Kobe earthquake in Japan, the American hurricane "Katrina", the big flood of 1996 in China are some cases in point[2]. Even worse, these natural disasters pose a threat to the traffic route for the relieve material. Since the traffic problem we have discussed so far has a direct bearing on the military/rescue task and the safety of the personnel, the research of uncertainty of the route selection is significant for both war and the natural disaster[3][4]. There are a lot of researches on the optimization of the traffic route, but few are concerned about the route selection in times of war/natural disaster, even less are the formal research literature. The present paper discusses the multi-vehicle route selection problem under the situation of certain key route section (bridge, tunnel, etc,) being destroyed and comes up with a math model and a taboo-heuristic algorithm for this model.

\section{The Description OF THE PROBlem AND THE ANALYSIS OF ITS COMPLEXITY}

\section{A. The Problem}

The sabotaged traffic problem can be described as follows: in the traffic map $G=(V, A), V=\left\{v_{0}, v_{1}, v_{2}, \cdots, v_{n}\right\}$ is the aggregate of vertex, $v_{0}$ stands for storing places, the vehicles start from this point for delivery, and return after the delivery.. the other $v_{i}$ stands for places in need of service, abbreviated as PNS. $A=\left\{\left(v_{i}, v_{j}\right)\left(i \neq j, v_{i}, v_{j} \in V\right\}\right.$ is the aggregate of arcs, each arc standing for the route between two vertexes. Within the aggregate $\mathrm{A}$, vector $C=\left\{c_{i j}\right\}$ is defined as the distance between two vertexes, the driving cost or time etc, The undirected arc $\left(b_{1}, b_{2}\right) \in A$ stands for a route that might be sabotaged at any time, with uncertain time and probability[5]. $\hat{G}$ Stands for the map in which the route is sabotaged, it shares the same features with $G$, except that the route value of $\operatorname{arc}^{\left(b_{1}, b_{2}\right)}$ is $\infty$. The demands of the customers are symbolized as $q_{i}$, which is guaranteed by $M$ vehicles whose maximum load is $Q$.

\section{B. The Complexity of the Problem}

Vehicle routing problem is publicly recognized as a NP difficult problem, which has $n$ ! candidate programs for $n$ demanding point. There are $2(n-1) !$ routing programs which include $\left(b_{1}, b_{2}\right)$ and $\left(b_{2}, b_{1}\right)$. In the program including $\left(b_{1}, b_{2}\right)$, if the route ahead is known to be sabotaged at the point $k(k \leq n)$, the route need to be researched all the points (including the point has passed) of the network, but at least has $(n-k) !$ programs. The least total number of the programs calculated is $n !-2(n-1) !+2(n-1) !(n-1) ! \approx n !+2(n-1) !(n-1) ! \quad$ at the point $k=1$. If $n=10$, the total number of the program is $2.6 \times 10^{11}$, if the evaluation value of each program is at least the sum between any two points. With the $1 \mathrm{G}$ main 
frequency of computer calculated, it will be needed about 0.72 hours[6]. If the case of $k>1$ and the whole network lines searched were taken into consideration, the time will be longer.

\section{MATHEMATICAL MODEL}

For any pre-planning of transportation program $R_{i}\left(r_{i 1}, r_{i 2} \cdots r_{i j} \cdots, r_{i M}\right)\left(r_{i j}\right.$ shows for the line of vehicle $\left.j\right)$, marked the demand point set of vehicle $j_{\text {for }} d_{j}$, then the set of all demand points is $D=\bigcup d_{j}$. When $r_{i j}$ does not include the possible damaged road sections, namely $\left(b_{1}, b_{2}\right) \notin r_{i j}$, the route in transit doesn't need adjusting[7]. If $\left(b_{1}, b_{2}\right) \in r_{i j}$, the vehicle $j$ is denoted by vehicle c. Marked the current position of vehicle $j$ is $h_{j}$, when get the information of the route has destroyed, (when the vehicle between the two demand point, return for the next demand point), the current position set of all the vehicles is $H=\left\{h_{j} \mid j \leq M\right\}$, The demand points set of vehicle ${ }^{j}$ has supported is $d-d_{j}^{\prime}$, and all remaining demand points set is $D-D^{\prime}$ [8]. The re-optimization of the remaining demand points of $r_{i b}$ is called non-collaborative optimization. And the re-optimization of all of the remaining demand points and the routes is called global collaborative optimization. The result of vehicle $b$ route re-optimization is related with the vehicle current position[9], the remaining demand points, and the diagram of damaged network. As the time of route destroyed is uncertain, so these factors above are uncertain. Therefore, the system is an uncertain two-stage program problem. All vehicles path model of cooperation can be expressed as follows:

$$
\begin{aligned}
& \min z=\sum_{i=0 j=0 n=1}^{n} \sum_{i j}^{M} c_{i j} x_{i j m}+\max \left(\sum_{m=1}^{M}\left(x_{b_{1}, m}+x_{b_{2}, m}\right)\right) \sum_{h_{b}=1}^{e} p_{h_{b}}\left[\min z^{\prime}-\sum_{r=0 \mathrm{~s}=1 m=1}^{n} \sum_{m=1}^{M} c_{r s} x_{r s b}\right] \\
& r, s \in\left(d-d^{\prime}\right) \cup\{0\} \\
& \min z^{\prime}=\sum_{m=1}^{M} \sum_{i=0}^{n} \sum_{j=0}^{n} c_{i j} x_{i j m}^{\prime} \\
& \sum_{i=1}^{n} \sum_{j=1}^{n} q_{j} x_{i j m} \leq Q_{m} \quad m=1, \cdots M \\
& \sum_{m=1}^{M} \sum_{i=1}^{n} x_{i j m}=1 \quad j \in d \\
& \sum_{m=1}^{M} \sum_{j=1}^{n} x_{i j m}=1 \\
& \sum_{m=1}^{M} \sum_{j=1}^{n} x_{0}=\sum_{j m}^{M} \sum_{i=1}^{n} x_{i 0 m}=m \\
& \sum_{m=1}^{M} \sum_{j=1}^{n} x_{h_{i} j m}^{\prime}=1 \\
& h_{i} \in H
\end{aligned}
$$

$$
\begin{aligned}
& \sum_{m=1}^{M} \sum_{i=1}^{n} x_{i 0 m}^{\prime}=M \\
& \sum_{m=1}^{M} \sum_{j=1}^{n} x_{i j m}^{\prime}=1 \quad i \in d^{\prime} \\
& \sum_{m=1}^{M} \sum_{i=1}^{n} x_{i j m}^{\prime}=1 \quad j \in d^{\prime} \\
& x_{b_{1} b_{2} m}^{\prime}=x_{b_{2} b_{1} m}^{\prime}=0 \\
& x_{i j m}=0,1, \quad x_{i j m}^{\prime}=0,1
\end{aligned}
$$

Formula (1) is a two-stage planning objective function, In the first phase of planning, when the vehicle passing through the road $(i, j),{ }^{x_{i j m}}$ is 1 , otherwise, ${ }^{x_{i j m}}$ is 0 . The first item in the left of the formula stands for the first planning line value, the second item stands for the re-optimized mileage subtracted by the mileage covered out of the first stage planning after the route was destroyed. Max is a switch function, when the routes is symbolized as 1 if it includes the possible damaged route, otherwise it is symbolized as $0 . e_{\text {is }}$ the serial number of the first node of the destroyed road section. ${ }^{p_{h_{b}}}$ is the probability of re-optimizing the route in position $h_{b} . \min z^{\prime}$ is the route value of the route reoptimization. $\sum_{r=1 s=0}^{n} \sum_{m=1}^{n} \sum_{m=1}^{M} c_{r s} x_{r s m}$ is planned in the first stage. But was not covered because of re-optimization Formula (2) is target function of the second phase planning. In the second phase planning, when the vehicle is passing the ( $i$, $j$ )section, ${ }^{x_{i j m}^{\prime}}$ is 1 , otherwise, ${ }^{x_{i j m}^{\prime}}$ is 0 . Formula (3)-(6)is the constraint conditions of the first phase planning. Formula 3 shows that the transportation demand of each vehicle must be smaller than the total vehicle load bearing[10]. Formula (4), (5)shows that each demand point can be accessed only once. Formula (6) makes sure the number of vehicles driven in and out of the warehouse remains the same, and also equals to the number of the implementation of vehicles. Formula (7)-(12) is the constraint conditions of the second phase planning. Formula (7) shows vehicles participated in collaboration starting from the current position, Formula (8) shows vehicles participated in collaboration returns warehouse. Formula (9) and (10) shows the remaining vehicles must pass in and out only once. Formula (11) shows vehicles cannot pass the road destroyed.

Adjusting some parameters of the model, a two-stage planning model of non-collaboration could be established. The process of it will not be elaborated here.

\section{Evaluation Value of the Route Program}

If each value of $p_{h_{b}}$ of formula $*$ (1) is taken into consideration in the algorithm, the algorithms will last a very long time. In addition, the damage pattern is difficult to find in the war environment, and in most cases, commanders only care about the worst and the best scenario. Therefore, 
program evaluation value can be reduced to evaluation only in the worst and the best cases.

\section{A. Maximum Value of the Program}

Marke the minimum mileage and the maximum mileage of route program $R_{i}$ for $\operatorname{best}\left(R_{i}\right)$ and ${ }^{\operatorname{worst}}\left(R_{i}\right)$. If the route did not adjust the line in the midway, the actual mileage of $R_{i} \quad$ is $f\left(R_{i}\right)$, the effectiveness of the program is $\quad u\left(R_{i}\right)=u\left(\operatorname{bes}\left(R_{i}\right)\right.$, wors $\left.\left(R_{i}\right)\right) \quad$. If $\quad\left(b_{1}, b_{2}\right) \notin R_{i}$ then $u\left(R_{i}\right)=f\left(R_{i}\right)=\operatorname{bes}\left(t R_{i}\right)=$ wor $\left(R_{i}\right)$. If $\left(b_{1}, b_{2}\right) \in R_{i}$, decision makers will make a second planning when getting the destroyed-road information. For the same information, the sooner the system get access to it , the better for decisionmaking. Therefore, the worst case should be they getting the road destroyed information when they are just in the first point of the destroyed road, so the entire mileage of transportation route is the longest. In a project $R_{i}$ including the possible damaged route, the route sequence number of the demanding point $\mathrm{k}$ for $r_{i b}$ is $s_{k}\left(R_{i}\right) ; f_{1}\left(s_{k}, R_{i}\right)$ is the whole mileage vehicle covered, in case of route reoptimization in the demanding point $k . f f\left(R_{i}(i, j)\right)$ shows for the mileages of all vehicles have covered, when the vehicle $b$ drives from demand point $i$ to demand point $j$. $f f\left(R_{i}^{\prime}\left(s_{k}\right)\right)$ shows for part of the mileage after route reoptimization in $S_{k}$.

Theorem 1 if $\left(b_{1}, b_{2}\right) \in R_{i}$, in the process of transportation the maximum mileage is $f\left(s_{e}, R_{i}\right)$, in which $s_{e}=\min \left(s_{b 1}, s_{b 2}\right)$.

Proof: According to the order of route, $f_{1}\left(s_{k}, R_{i}\right)=f f\left(R_{i}\left(0, s_{k}\right)+f f\left(R_{i}^{\prime}\left(s_{k}\right)\right)\right.$

Similarly:

$$
f_{1}\left(s_{e}, R_{i}\right)=f f\left(R_{i}\left(0, s_{e}\right)+f f\left(R_{i}^{\prime}\left(s_{e}\right)\right)\right.
$$

$f_{1}\left(s_{e}, R_{i}\right)-f_{1}\left(s_{k}, R_{i}\right)=f f\left(R_{i}\left(s_{k}, s_{e}\right)\right)+R_{i}^{\prime}\left(s_{e}\right)-R_{i}^{\prime}\left(s_{k}\right)$

In formula ( 5$): R_{i}\left(s_{k}, s_{k}\right)+R_{i}^{\prime}\left(s_{e}\right), R_{i}^{\prime}\left(s_{k}\right)$, $R_{i}^{\prime}\left(s_{k}\right)$ shows a route for a supporting $R_{i}$ after the point $s_{k}$, as $R_{i}^{\prime}\left(s_{k}\right)$ is the optimized route, so $f\left(s_{e}, R_{i}\right) \geq f\left(s_{k}, R_{i}\right)$, and the conclusion is proved.

Minimum Value of the Program

According to Theorem 1, the minimum mileage of route adjustment in $R_{i}$ is $f_{1}\left(s_{1}, R_{i}\right)$. If $f\left(R_{i}\right) \leq f\left(s_{1}, R_{i}\right)$, then the minimum value of the program is $f\left(R_{i}\right)$. If $f\left(R_{i}\right)<f\left(s_{1}, R_{i}\right)$, then the minimum value of the program is $f\left(s_{1}, R_{i}\right)$. But if the minimum value of program evaluation is $f\left(s_{1}, R_{i}\right)$, the algorithm time will be much longer. It will be proved that if we take $f\left(R_{i}\right)$ as the minimum value of the program it does not affect the results of the selection.

If we mark $R$ as the best program planned in chart $\hat{G}$, the route after adjustment inevitably contains damaged sections, so $f\left(s_{1}, R_{i}\right)<f(R)$. The maximum value and the minimum value are took for the evaluation value of the parameters: $u\left(R_{i}\right)=u\left(\operatorname{best}\left(R_{i}\right), \operatorname{worst}\left(R_{i}\right)\right)$

$\operatorname{worst}\left(R_{i}\right)=f\left(s_{b}, R_{i}\right) \quad, \quad \operatorname{best}\left(R_{i}\right)=f\left(s_{1}, R_{i}\right) \quad$, clearly $\operatorname{worst}\left(R_{i}\right)>\operatorname{best}\left(R_{i}\right) \geq f(R)$, namely $u\left(R_{i}\right)>u(R)$, the revision of the evaluation value is $u^{\prime}\left(R_{i}\right)=u\left(f\left(R_{i}\right), \operatorname{worst}\left(R_{i}\right)\right)>u\left(R_{i}\right) \quad, \quad$ because $u^{\prime}\left(R_{i}\right)>u\left(R_{i}\right)>u(R)$, the program will be eliminated no matter what evaluation value was taken. The conclusion is proved.

\section{TABOO SEARCH ALGORITHM}

Taboo search algorithm is mainly as follows:

(1) A path sequence randomly generated for initial solution. Serial number $\mathrm{n}$ demand points, warehouse point is 0 . Both of the head and the end of the path solution are 0 , the middle one is a random arrangement of $\mathrm{n}$ demand point plus 0 , the number of 0 is $M-1$. Between two 0 nearby is a vehicle service path. Took six demand point and two vehicles for example, a path solution is $0-1-2-3-0-4-5-6-0$.

(2) The generation of the neighborhood. Any two demand points were used to exchange places, any demand point is inserted into the routes at any position of method to generate new solutions.

(3) Handling vehicle capacity limit. When a vehicle's total demand in a demand point exceeds the maximum cargo capacity of vehicle, the program was eliminated.

(4) Taboo object is two adjacent demand points. The length of taboo list increases with the evolution of extended algebra. When the present value is superior to the optimal of history value, taboo was lifted.

(5) Program evaluation value. Each program was respectively calculated the minimum mileage $F_{1}\left(r_{i}\right)$ and maximum mileage $F_{2}\left(r_{i}\right)$. Calculating the path of destruction section contains the largest mileage, point-topoint posterior all remaining customers use an inner taboo search algorithm, the algorithm of the basic method and outer algorithm is same. Final evaluation value was based on various decision criteria to determine. Generally have maxmax criterion, max-min criterion, rubrics criterion and expectation criterion, the rules of specific provision can refer to reference (1) and (2).

(6) Route direction. In max-max criterion, route adjustment after destroyed is not calculated to evaluation value. In order to remedy this defect, it can be selected optimal program and a number of sub-optimal solutions under max-max criterion, and calculated the worst case result for decision-making. Even it is the best program, the same route order but different route direction is also considered 
various solutions. Such as route $0-1-2-3-4-0$ and 1-0-0-4-3-2 are different programs.

\section{EXAMPLE}

Table 1 is a distance data of network, section 2-4 passes a bridge which is difficult to repair, probably destroyed by the enemy. 0 means warehouse, other 10 serial number mean demand points, each demand point demand for 5, the largest carrying capacity of each vehicle is 35 , The shortest mileage route under different expectations criterion was planned with two vehicles delivery.

Because of the vehicle load limit, the task must be completed by two vehicles. The taboo search algorithm used to get the best program under different criterions.

\section{Closing}

Logistics transportation support in wartime or all kinds of rescue and relief is of great significance. But there is little research about this kind of transportation route optimization problem. The paper combined uncertain decision technique and vehicle routing optimization technique, set up the route optimization model in uncertain environment transportation, and the research results can be used for providing logistics decision reference in uncertain environment.

\section{REFERENCES}

[1] Dantzig G, Ramser J. The truck dispatching problem [J].Management Science, 1959,6: 8091

[2] Moritz F, Jacqueline M, Bloemhof R, et al. Quantitative models for reverse logistics: A review [J].European Journal of Operational Research, 1997,103: 117.

[3] Chopra S, Meindl P. Supply Chain Management, Strategy,Planning, and Operation [M]. New Jersey: Prentice Hall,2001.

[4] Paolo T, Daniele V. Models, relaxations and exact approaches for the capacitated vehicle routing problem [J].Discrete Applied Mathematics, 2002,123: 487512.

[5] Harrison H. Management science and productivity improvement in Irish Milk cooperative [J].Interface, 1986,16(4): 3140.

[6] Cheong Y M, Ong H L, Huang H C. Modeling the vehicle routing problem for a soft drink distribution company [J]. Asia-Pacific Journal of Operational Research, 2002,19:17 34

[7] Beasley J E, Christofides N. Vehicle routing with a sparse feasibility graph [J].European Journal of Operational Research, 1997,98(3): 499 511.

[8] Golden B L, Wasil E A. Computerized vehicle routing in the soft drink industry [J].Operation Research, 1987,35(1): 617.

[9] Gilbert L, Gendreau M, Potvin J Y, et al. Classical and modern heuristics for the vehicle routing problem [J]. International Transactions in Operational Research, 2000,7: 285300.

[10] Lin S, Kernighan B W. An effective heuristic for the traveling salesman problem [J].Operation Research, 1973,15: 577584.

TABLE I. THE DISTANCE BETWEEN SECTIONS

\begin{tabular}{|c|c|c|c|c|c|c|c|c|c|c|c|}
\hline $\begin{array}{r}\text { Serial } \\
\text { Numpber }\end{array}$ & 0 & 1 & 2 & 3 & 4 & 5 & 6 & 7 & 8 & 9 & 10 \\
\hline 0 & 0 & 1000 & 38 & 37 & 45 & 25 & 1000 & 26 & 41 & 52 & 40 \\
\hline 1 & 1000 & 0 & 1000 & 14 & 1000 & 1000 & 39 & 36 & 1000 & 37 & 1000 \\
\hline 2 & 28 & 1000 & 0 & 1000 & 25 & 28 & 36 & 1000 & 1000 & 1000 & 1000 \\
\hline 3 & 27 & 14 & 1000 & 0 & 40 & 1000 & 1000 & 1000 & 1000 & 15 & 44 \\
\hline 4 & 45 & 1000 & 25 & 40 & 0 & 1000 & 1000 & 1000 & 1000 & 1000 & 1000 \\
\hline 5 & 25 & 1000 & 28 & 1000 & 1000 & 0 & 10 & 25 & 13 & 1000 & 1000 \\
\hline 6 & 1000 & 39 & 36 & 1000 & 1000 & 10 & 0 & 25 & 19 & 1000 & 1000 \\
\hline 7 & 36 & 36 & 1000 & 1000 & 1000 & 25 & 25 & 0 & 12 & 1000 & 14 \\
\hline 8 & 41 & 1000 & 1000 & 1000 & 1000 & 13 & 29 & 12 & 0 & 1000 & 31 \\
\hline 9 & 1000 & 17 & 1000 & 15 & 1000 & 1000 & 1000 & 1000 & 1000 & 0 & 30 \\
\hline 10 & 30 & 1000 & 1000 & 34 & 1000 & 1000 & 1000 & 14 & 41 & 40 & 0 \\
\hline
\end{tabular}

TABLE II. THE ROUTE OPTIMIZED RESULT OF SECTIONS 2-4 MAY BE DAMAGED

\begin{tabular}{|c|c|c|c|c|c|c|}
\hline \multicolumn{2}{|c|}{ Decision Criteria } & \multicolumn{2}{|r|}{ Best-case } & \multicolumn{2}{|r|}{ Worst-case } & \multirow{2}{*}{\begin{tabular}{|c|c}
$\begin{array}{c}\text { The Value of the } \\
\text { Program Evaluation }\end{array}$ \\
323
\end{tabular}} \\
\hline Max-min C & Criterion & 323 & 77856204313910 & 323 & 7856204313910 & \\
\hline \multirow{2}{*}{$\begin{array}{l}\text { Max-max } \\
\text { Criterion }\end{array}$} & Cooperation & 301 & 710913042685 & 323 & 7856204313910 & \multirow[b]{2}{*}{301} \\
\hline & Non-cooperation & 301 & 710913042685 & 382 & 710913043178562 & \\
\hline \multirow{2}{*}{$\begin{array}{l}\text { Rlurwicz } \\
\text { Criterion }\end{array}$} & Cooperation & 301 & 710913042685 & 323 & 7856204313910 & 312 \\
\hline & Non-cooperation & 324 & 439162058710 & 324 & 439162058710 & 324 \\
\hline
\end{tabular}

